François Ost y Mark van Hoecke

\author{
«DEL CONTRATO A LA \\ TRANSMISIÓN. SOBRE \\ LA RESPONSABILIDAD HACIA \\ LAS GENERACIONES FUTURAS»
}




\title{
DEL CONTRATO A LA TRANSMISIÓN. SOBRE LA RESPONSABILIDAD HACIA LAS GENERACIONES FUTURAS
}

\author{
François Ost y Mark van Hoecke \\ Academia Europea de Teoría del Derecho (Bruselas)
}

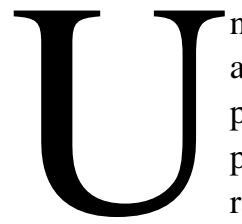

na de las mayores dificultades para la protección del medio ambiente tiene que ver con el uso de diferentes escalas temporales: una temporalidad corta, o incluso muy corta, para los proyectos políticos y las previsiones jurídicas, y una temporalidad larga, o incluso muy larga, para los ciclos y procesos ecológicos. Sin embargo, la idea que hoy se ha impuesto es que la protección del medio ambiente es una cuestión a largo plazo, lo que implica importantes modificaciones en nuestros paradigmas: el economista aprende a razonar en términos de desarrollo sostenible, el jurista habla de transmitir un patrimonio, el moralista se refiere a la responsabilidad hacia las generaciones futuras.

Un reajuste tan fundamental de nuestra manera de ver las cosas necesita una buena base filosófica y tomar en cuenta sus efectos. No obstante, aparecen al menos dos grandes obstáculos generados por la toma en consideración del futuro en los planos ético, jurídico y político (al margen de las dificultades ligadas a las incertidumbres inherentes a la predicción del futuro). Por un lado, está el problema de las implicaciones del modelo ético «contractualista», que sólo reconoce obligaciones entre sujetos aproximadamente iguales e implicados en relaciones de intercambio recíprocamente obligatorias; aquí la cuestión es cómo extender la comunidad ética de modo que incluya sujetos que todavía no existen, respecto a los cuales estamos en una relación totalmente asimétrica. Por otro lado, está el problema de la «miopía temporal» de nuestra era, que presenta al mismo tiempo amnesia respecto al pasado, incluso respecto al pasado reciente, e incapacidad para proyectarnos en un futuro con sentido. Es de la discusión de estos dos obstáculos de lo que aquí nos ocuparemos.

\section{El obstáculo contractualista}

Al menos desde la modernidad, las cuestiones de justicia han sido pensadas en términos de contrato, de simetría y de reciprocidad. Es lo que $\mathrm{Hu}$ - 
me llamaba las «circunstancias de la justicia»: un medio ambiente caracterizado por la relativa escasez de los bienes disponibles, una sociedad compuesta por personas cuyo altruismo es moderado y cuyas fuerzas son relativamente iguales. En tal contexto, es racional y prudente aceptar ciertas limitaciones a nuestra libertad con el fin de garantizar la seguridad física y material de nuestra existencia. El resto de la historia es bien conocido: se imagina un gran contrato social para fundar la sociedad política y se celebran una multitud de contratos privados para garantizar el respeto y, si es posible, el incremento de la propiedad. El ideal de reciprocidad irradia en el conjunto del campo ético; toma formas tan variadas como la idea de equidad, el respeto a la palabra dada, o incluso la práctica mutualista. En esta tradición, la moral tiene por objeto ofrecernos buenas razones para abstenernos de dañar a todos aquéllos que, en virtud de su igualdad aproximada, podrían constituir un peligro para nosotros. Desde este punto de vista, la cuestión de las generaciones futuras queda excluida del ámbito de la ética, ya que tales generaciones son incapaces de afectarnos en absoluto. El contractualismo constituye entonces un obstáculo para concebir las obligaciones respecto a las naciones pobres y lejanas y, a fortiori, respecto a las generaciones futuras ${ }^{1}$.

Es interesante constatar que las dos teorías contemporáneas, la de J. Rawls y la de J. Habermas, que han intentado redefinir las condiciones iniciales para una discusión equitativa de las normas y principios válidos de justicia han sido incapaces de liberarse del modelo de la reciprocidad, de modo que no logran ofrecer una respuesta satisfactoria para fundamentar la idea de responsabilidades hacia las generaciones futuras. En la obra de Rawls, los negociadores situados en la posición originaria bajo el velo de la ignorancia son contemporáneos: los principios sobre los cuales se basa su acuerdo son, por ello, concebidos «para su propia ventaja mutua» como principios de cooperación racional entre personas aproximadamente iguales. Se incluye un principio de ahorro, pero limitado a las necesidades previsibles de las dos generaciones siguientes (la de sus hijos y la de sus nietos), que son de las que cada generación se preocupa espontáneamente ${ }^{2}$. Si no se incluyen en la negociación representantes de todas las generaciones, se compromete seria-

${ }^{1}$ Cf. B. BARRY, Justice between Generations, en Law, Morality and Society. Essays in Honour of H.L.A. Hart, Oxford, 1979, p. 272; idem., Circumstances of Justice and Future Generations, en Obligations to Future Generations, ed. por R.I. Sikora \& B. Barry, Philadelphia, 1978, pp. 204 y ss.; idem, Justice as Reciprocity, en Justice, E. Kamenka \& A. Erh-Soon Tay (eds.), Londres, 1979, pp. 50 y ss.

2 J. RAWLS, Théorie de la justice, trad. por C. Audard, París, 1987, pp. 324 y ss.; para una discusión sobre este punto, véase B. BARRY, Circumstances of Justice..., op. cit., pp. 228 y ss.; idem, Theories of Justice, vol. I, Londres, 1989, pp. 183 y ss. Sin embargo, debería ser obvio que la teoría de Rawls puede fácilmente incluir a las generaciones futuras, a condición de considerar que el «velo de la ignorancia» incluya también la ignorancia temporal, de modo 
mente la pretensión de universalidad, incluso tal y como dicha pretensión se incluye en la teoría de Rawls, vista aquí en su aspecto kantiano. Del mismo modo, la preocupación por las generaciones futuras queda limitada a la cuestión de «transferencias justas» entre generaciones contiguas (generaciones entendidas como «grupos de edad», es decir, como categorías definidas por el período de vida en el que se encuentran: los jóvenes, los adultos y las personas mayores), prescindiendo de la cuestión de la «justa herencia» entre «cohortes» (generaciones entendidas esta vez como categorías de personas definidas por su fecha de nacimiento: en este sentido las «cohortes» pueden aludir a grupos a veces muy distantes unos de otros) ${ }^{3}$.

La ética comunicativa de Habermas tiene también, como él mismo admite, dificultades para contestar a la pregunta que le plantea la ética ecológica: «¿Cómo una teoría que se limita al círculo de destinatarios capaces de hablar y de actuar puede aplicarse a la vulnerabilidad de una criatura muda?» ${ }^{4}$. Ante esta pregunta, formulada por él mismo, Habermas sólo encontrará dos vías de escape. En un pasaje se refiere a un «concepto estricto de la moral» acompañado de «una autocomprensión modesta de la teoría moral», limitándose a pensar en las condiciones de un procedimiento justo de negociación, mientras que deja a los negociadores a su propia intuición por lo que respecta a las exigencias de la vida buena ${ }^{5}$. En otro pasaje escribe que, respecto a la cuestión medioambiental, «las razones estéticas pesan en ciertos aspectos más que las razones éticas»: si las cosas de la naturaleza son tan vulnerables en su «inabordable virginidad», ¿no aparecerían entonces como «intocables» ${ }^{6}$ ?

Resulta obvio que la ética discursiva no está en condiciones de superar el desafío que le plantean las exigencias de preservación de las generaciones futuras ${ }^{7}$. La acción comunicativa presupone «relaciones fundamentales

que en el momento de decidir la distribución justa de bienes y recursos no se sepa en qué período de tiempo se ha nacido. Para un análisis de la posición de Rawls y el problema de la responsabilidad hacia las generaciones futuras: H.Ph. VISSER't HOOFT, Justice to Future Generations and the Environment, Law and Philosophy Library, vol. 40, Kluwer Academic Publishers, Dordrecht/Boston/London, 1999, pp. 63-97. Este autor lleva a cabo varias observaciones de interés, sobre el problema de la justicia intergeneracional, usando las ideas de Rawls de mejor modo que el propio Rawls.

${ }^{3}$ Sobre la distinción entre la cuestión de «transferencia justa» entre «grupos de edad» y la cuestión de «herencia justa» entre «cohortes», cf. Ph. VAN PARIJS, La justice entre générations, en Wallonie, 1995-5, n 41, pp. 7 y s.

${ }^{4}$ J. HABERMAS, De l'éthique de la discussion, trad. Por M. Hunyadi, París, 1992, p. 31.

5 Ibid., pp. 31-32.

${ }^{6}$ Ibid., pp. 198-199.

${ }^{7}$ Cf. K.O. APEL, L'éthique du discours comme éthique de la responsabilité: une transformation postmétaphysique de l'éthique Kantienne, en Revue de métaphysique et de morale, n 4, 1993, pp. 505-537; idem, Éthique de la discussion, trad. M. Hunyadi, París, 1994. 
de reciprocidad» $\mathrm{y}$, en este contexto, la integridad de la persona descansa sobre una «red de reconocimientos simétricos» entre los miembros de una misma comunidad $^{8}$. Mientras que las relaciones de responsabilidad entre las generaciones presentes y futuras se caracterizan por una falta completa de simetría, el ideal de comunidad comunicativa propuesto por Habermas presupone lo contrario, la perfecta reversibilidad del criterio de validez formulado por los sujetos razonables que toman parte en la deliberación ${ }^{9}$. A decir verdad, éstos son los dos principios fundamentales de la ética comunicativa que vamos a polemizar aquí. El principio de la discusión (el principio «D»), que establece que sólo pueden pretender la validez aquellas normas capaces de conseguir el acuerdo del conjunto de los participantes en la discusión práctica, no parece dar cabida a los intereses de las personas no representadas, y especialmente de las generaciones pasadas y futuras. De modo similar, el principio de universalización (el principio «U») es también problematizado, ya que establece que para que una norma sea válida, sus consecuencias y sus previsibles efectos secundarios deben poder ser aceptados por todos sin restricciones. Pero nadie ignora que la problemática ecológica implica precisamente la dificultad de prever las consecuencias a largo plazo de algunas de nuestras políticas actuales, que pueden llegar a ser catastróficas.

Parece entonces que, incluso reformulado en términos no mercantiles, el modelo contractualista-procedimental no está a la altura del desafío planteado por la responsabilidad hacia las generaciones futuras. Sin que sea necesario abandonar la idea de equilibrio o de igualdad, que se corresponde con una intuición ética tan profunda como tenaz, las ideas de contrato, de simetría y de reciprocidad exigen como mínimo ser seriamente repensadas. Nuestra hipótesis de trabajo es que el modelo de la transmisión que envuelve y desborda al del intercambio sinalagmático, puede ser de gran ayuda. Pero antes es necesario abordar un segundo obstáculo, relativo esta vez a la concepción del tiempo, «instantaneísta» y «simultaneísta», privilegiada por nuestra modernidad.

\section{El obstáculo «instantaneísta»}

Del mismo modo que la idea de reciprocidad, el modelo contractualista incluye la presuposición de que la historia comienza con la celebración de un contrato. Todo ocurre como si los negociadores, saliendo de un obscuro estado de naturaleza, escribieran la historia y fundaran la sociedad desde

\footnotetext{
${ }^{8}$ Ibid., p. 196.

${ }^{9}$ En este sentido, cf. J. GREISCH, Présentation, en H. JONAS, Le principe responsabilité, trad. por J. Greisch, París, 1990, p. 12.
} 
una «tabula rasa», a partir del punto cero de la juridicidad que estaría constituido por el contrato a celebrar. Se perfila algo así como una fantasía de autocreación o de un principio absoluto; se trata indudablemente de una de las últimas consecuencias del individualismo moderno. Se corta claramente la transmisión, haciendo creer que es posible interrumpir la cadena de generaciones sucesivas, y se trata a las cuestiones de justicia según el eje horizontal de la simultaneidad, dejando de lado el eje vertical de la sucesión. Es como si a cada generación le correspondiera rehacer el mundo y redefinir completamente, a través de la mesa de negociación, las condiciones del intercambio justo.

Si retomamos las categorías de «espacio de la experiencia» y de «horizonte de expectativa» que P. Ricoeur toma de R. Koselleck, cuya interacción define, según este autor, el tiempo histórico ${ }^{10}$ (es decir, el tiempo significativo, reapropiado por la cultura) -y si admitimos que «el espacio de la experiencia» recapitula el pasado con miras a encontrar recursos hermenéuticos para el presente y que «el horizonte de expectativa» abre un ámbito de superación en el que inscribir los proyectos para el futuro-, se podría lanzar la hipótesis de que, en la cultura contemporánea, esas dos categorías no cesan de distanciarse, dejando el presente cada vez más «vacío» y menos capaz de articular el pasado y el futuro con el propósito de trazar líneas de actuación que muestren el camino a seguir. Todo eso ocurre como si, con la aceleración siempre creciente de la historia y la creencia, siempre vivaz, de que los hombres son totalmente responsables de cada instante de esta historia, el «espacio de la experiencia» perdiera toda consistencia y pertinencia, mientras que el futuro apareciera cada vez más abierto e incierto. Entre los dos se abre entonces el presente, que es saturado, en compensación, con mensajes instantáneos que se transmiten en tiempo real: la simultaneidad, cada vez más compacta, de la comunicación es también tomada en cuenta para compensar lo que se pierde en términos de inserción en un período significativo de tiempo. A causa de la falta de un vínculo vivo entre el pasado y el futuro, cada referencia a la tradición es condenada a aparecer como rigidez ideológica, si no fundamentalismo agresivo; mientras que la formulación de proyectos para el futuro sólo se da bajo la depreciada forma de la utopía.

Esta situación cultural no está exenta de consecuencias para nuestra problemática. Ella vuelve difícilmente aceptable la idea de que la generación presente pueda ser afectada por las generaciones pasadas y por las futuras. Si cada generación se auto-instituye, si cada época, o incluso cada instante, sólo se funda sobre sí mismo, ¿qué tipo de deudas o créditos podemos ha-

\footnotetext{
${ }^{10}$ P. RICOEUR, Temps et récit, T. III, París, 1985, p. 302.
} 
cer valer respecto a nuestros predecesores y sucesores? Esta «miopía temporal» compromete radicalmente la discusión de las responsabilidades hacia las generaciones futuras. Como señala John O'Neill, la mayor parte de las teorías morales, incluso aquéllas que parecen las mejor intencionadas respecto a las generaciones futuras, se encuentran afectadas por este presupuesto: nuestros sucesores no pueden afectarnos de ningún modo; no sabrían ni perjudicarnos, ni favorecernos ${ }^{11}$. Habrá quienes extraigan la consecuencia lógica de que, al no participar en la misma comunidad ética, no se tiene ningún tipo de deber hacia ellas. Otros, preocupados al menos por no comprometer el futuro, intentarán establecer responsabilidades a este respecto, pero como si se tratara de personas radicalmente ajenas o diferentes. Se formulan entonces deberes, pero bajo la forma de normas puramente abstractas en el mundo congelado de la especulación racional; a veces de modo francamente insólito, como en ciertos raciocinios utilitaristas relativos a la incidencia de la decisión de procrear en la suma o la media de bienestar global de las generaciones futuras destinadas a vivir en un medio ambiente afectado él mismo por la cantidad de población futura ${ }^{12}$. Todo esto parece expresar una pérdida completa del sentido de la comunidad temporal que vincula entre sí a las generaciones; el bien de cada generación, la felicidad que puede esperar, es una cuestión puramente local y contingente, no tiene nada que ver ni con las generaciones pasadas ni con las futuras; por el contrario, no tiene ningún deber a su respecto (salvo, como hemos dicho, en el caso de las teorías que intentan fundamentar obligaciones que son puramente impersonales, privadas de cualquier tipo de vínculo con un sentido vivo de la transmisión). En este contexto, hay un gran riesgo de que cada generación adopte por su cuenta, y esta vez en el plano temporal, el comportamiento irresponsable que describe Hardin en «The Tragedy of Commons»: liberados de las ataduras de la solidaridad histórica, cada uno tendrá sin duda la tentación de maximizar sus beneficios sin demasiada preocupación por el futuro, o incluso cargando sobre las generaciones siguientes las consecuencias de los riesgos, los préstamos, la contaminación y la disminución de los recursos ${ }^{13}$.

${ }^{11}$ J. O'NEILL, Ecology, Policy and Politics, Londres, 1993, pp. 27 y ss.

${ }^{12}$ Cf., por ejemplo, D. BIRNBACHER, La responsabilité à l'égard des générations futures, trad. por O. Mannoni, París, 1994, pp. 90 y ss.; cf. también el «problema de no-identidad» discutido por D. PARFIT (Reasons and Persons, Oxford, 1984, pp. 351-379): adoptar una política ecológica desastrosa no afecta a nadie en particular, ya que, en virtud de la propia elección, el número y la identidad de las personas futuras se encuentran automáticamente modificados.

${ }^{13}$ G. HARDIN, The Tragedy of Commons, en G. Hardin y J. Baden (eds.), Managing the Commons, San Francisco, 1977. 
Este catastrófico escenario no es, sin embargo, ineludible. El aislamiento temporal, en el que a cada generación le gustaría verse envuelta, es desmentido por un hecho evidente que implica al menos a tres generaciones, la de los adultos, la de los niños y la de las personas mayores, cuyas necesidades, contribuciones y visiones del mundo tienden, por tanto, a enlazarse al menos parcialmente. Este dato antropológico natural tiene el mérito de concretar y de volver de alguna forma tangible la intuición ética más abstracta de la cadena histórica de generaciones y de la interacción de lo que llamamos «el espacio de la experiencia» y «el horizonte de expectativa». En la actitud que manifiesta la generación de los adultos hacia los más jóvenes y los más viejos se comprueba la credibilidad de las políticas y de los valores adoptados (o no) respecto a las generaciones más alejadas. La cuestión de las «transferencias justas», sin ser necesariamente lo mismo que la «herencia justa», obliga al menos a la generación adulta a salir de su autarquía y preguntarse qué papel pretende desempeñar en la lógica de la transmisión.

\section{Otra perspectiva: la transmisión intergeneracional}

Resumamos. La responsabilidad hacia las generaciones futuras sólo puede fundamentarse si se superan dos obstáculos: la idea de que sólo se justifican las obligaciones recíprocas y aceptadas por cada una de las personas afectadas (contractualismo) y la presuposición según la cual las generaciones lejanas no pueden afectarnos en absoluto (instantaneismo). Hay, por supuesto, autores que han intentado esquivar estos dos obstáculos, pero provocando a su vez otros problemas. Pensamos, por ejemplo, en Hans Jonas, quien, consciente de esos dos límites de lo que él llama las morales tradicionales, pretende basar su nuevo imperativo categórico («hacer que el futuro sea»; reformulación de la pregunta de Leibniz: «¿Por qué es necesario que algo sea más que nada?») en una ontología de la vida: el hecho mismo de la existencia de la vida crea la obligación de que ella exista. Esta tesis plantea importantes cuestiones filosóficas que no abordaremos aquí ${ }^{14}$. Nuestra estrategia es diferente: queremos abordar de frente los dos obstáculos descritos, argumentando, en una perspectiva que resulte claramente humanista, a favor de una extensión del ámbito ético y jurídico a las generaciones futuras, partiendo para ello de la naturaleza de la propia humanidad. Nuestra tesis es que, por muy legítima que sea la reivindicación de au-

${ }^{14}$ Para una discusión desde un punto de vista fundamentalmente negativo, cf. J.M. FERRY, Les puissances de l'expérience, T. I, París, 1991, pp. 9 y ss.; y desde un punto de vista más positivo, cf. P. RICOEUR, La responsabilité et la fragilité de la vie, en Le messager européen, $1991, \mathrm{n}^{\circ} 5$, pp. 203 y ss. 
tonomía y de individualidad, no sería nada, o no gran cosa, fuera de la cadena de las generaciones. De este modo, la intersubjetividad de las interacciones lingüísticas es el primer y fundamental indicio, con la condición de entenderlo tanto como práctica horizontal de la comunicación, como norma vertical de la transmisión.

Habrá entonces que demostrar que los seres humanos están constituidos de tal manera, incluyendo sus demandas justificadas de autonomía, que exigen existir en un período de tiempo histórico el cual no termina ni con el individuo ni con la generación del individuo. Una vez que se establece esto, se siguen dos importantes consecuencias. La primera es que la categoría del contrato, omnipresente en nuestras figuras de legitimidad, podrá dar paso a la categoría de la responsabilidad, de manera que se pueda liberar de la sujeción de la simetría de las relaciones bilaterales de intercambio. La igualdad de principio de cada generación (y de cada uno de sus miembros) se establecerá, cualquiera que sea su situación en la cadena genealógica, de modo que se les reconozca un igual derecho de acceso a los recursos naturales. La idea de transmisión de un patrimonio se substituirá así por el modelo de intercambio comunicativo. Haciendo esto se restablecerá un modo de equilibrio en el núcleo mismo de una situación necesariamente asimétrica: la transitividad de la deuda (exigida o reconocida) entre generaciones sucesivas reemplazará a la igualdad compensatoria inherente a las relaciones mutuamente vinculantes entre contemporáneos. Desde esta perspectiva, propondremos una reinterpretación de la «regla de oro» ética. A continuación será posible derivar una segunda consecuencia de nuestra tesis inicial: una rehabilitación del tiempo histórico que, restaurando una relación de fecundidad recíproca del pasado («espacio de la experiencia») y del futuro («horizonte de expectativa»), será capaz -esperamos- de superar el obstáculo «instantaneísta».

El núcleo de nuestra argumentación consiste entonces en mostrar que es a partir de lo que el hombre es en sí mismo, y no de cualquier otro requisito exterior (la razón utilitarista, las exigencias de la vida, un mandamiento de Dios...), de lo que se hace valer el cuidado de las generaciones futuras. Quizás el concepto kantiano de humanidad es la mejor expresión de esta intuición. Como es sabido, los seres humanos son, para Kant, dignos de respeto en la medida en que son autónomos o, mejor dicho, al mismo tiempo sujeto y objeto de la ley moral. Esa es su humanidad: lo que hay en ellos de específicamente humanos, la facultad de determinarse en términos de la ley moral. El más alto imperativo, formulado en la segunda versión del imperativo categórico, consiste precisamente en respetar incondicionalmente esta humanidad («actúa de tal modo que trates a la humanidad, tanto en tu persona como en la persona de cualquier otro, siempre al mismo tiempo como 
un fin, y nunca sólo como un medio» ${ }^{15}$. Sin embargo, esta idea de humanidad no se limita en Kant al sujeto autónomo (que sería entonces autosuficiente, autárquico), sino que abarca también a la Humanidad con mayúscula, al conjunto de la raza humana, cuya tarea en la perspectiva histórica del «reino de los fines» es lograr finalmente su humanidad. La conquista por el hombre de su propia humanidad supone entonces una progresión indefinida que se encuentra al mismo tiempo indeterminada, en la medida en que se entiende como «perfectibilidad» ajena a la realización de todo modelo predeterminado, y determinada, en la medida en que es parte de un progreso continuo a través de las sucesivas generaciones. Desde este punto de vista, puede decirse que la humanidad de la Humanidad se define por el proyecto que ella misma se da; un plan que sólo tiene sentido cuando se extrapola en un futuro sin duda lejano y que se basa, por ello, en la colaboración de los que vendrán después. En contra de Mendelssohn, que considera una «quimera» la idea de que con el paso del tiempo la humanidad siempre se perfeccione, Kant sostiene la tesis de un progreso constante (aunque ocasionalmente interrumpido) en el desarrollo de la moralidad. «Me baso -escribe- en el deber inherente a cada miembro de las generaciones sucesivas de procurar que la posteridad no cese de mejorarse y de que, de este modo, este deber se transmita regularmente de un miembro a otro de las diferentes generaciones» ${ }^{16}$. En Kant esta «esperanza de tiempos mejores» se nutre de la afirmación de ese deber que, a su vez, «inflama el corazón humano» ${ }^{17}$; de este modo, el principio de «esperanza» y el principio de «responsabilidad», lejos de ser mutuamente exclusivos (como en ciertos pasajes de la obra de H. Jonas), tienden por el contrario a reforzarse mutuamente. Eso sin contar que además Kant apuesta por una especie de «ardid de la razón» para llevar a los hombres a tomar, a veces incluso a su pesar, el camino del deber: de este modo se ha pasado, en las relaciones interindividuales, del estado de naturaleza a la sociedad civil por medio del contrato social. Similarmente, las relaciones entre naciones pasarán del estado de guerra actual, a un régimen basado en una federación global bajo una constitución cosmopolita ${ }^{18}$. «El amor que cada generación se profesa a sí misma» servirá para establecer una paz universal ${ }^{19}$. El respeto del contemporáneo por su propia humanidad es entonces la mejor garantía para la toma en consideración de los lejanos sucesores.

${ }^{15}$ E. KANT, Fondament de la métaphysique des moeurs, París, 1971, p. 150.

${ }^{16}$ E. KANT, Sur l'expression: «Il se peut que ce soit juste en théorie, mais en pratique cela ne vaut rien», trad. L. Guillermit, París, 1967, p. 53.

17 Ibidem, p. 54.

${ }^{18}$ Ibidem, p. 57.

${ }^{19}$ Ibidem, p. 59. 
Se podría mostrar, aunque no es nuestro propósito, cuánto conserva este análisis de filosofía moral de las enseñanzas del psicoanálisis respecto a la condición humana. Condición que tiene sus orígenes en el endeudamiento (para la vida y la sucesión) y que se desarrolla en el modo en el que, como donantes, asumimos y transmitimos la herencia (al mismo tiempo, un regalo y una carencia) que hemos recibido de acuerdo con una lógica compleja e intemporal, para la cual dar es siempre, de alguna manera, recibir, y recibir es también dar en devolución ${ }^{20}$.

Estas breves indicaciones nos deberían permitir superar los obstáculos «contractualista» e «instantaneísta» para el establecimiento de una responsabilidad hacia las generaciones futuras. Por un lado, permiten pensar las cuestiones de justicia social en un cuadro más amplio y más realista que el del simple intercambio contractual. Concebir la justicia a partir únicamente del modelo del contrato es, en algún sentido, tomar en cuenta el curso de la historia de un modo puramente abstracto, para el que sólo habría adultos surgidos de la nada buscando maximizar sus intereses respectivos según una lógica puramente contable y sin tener que rendir cuentas a nadie, como si la historia fuera a terminarse al final de la partida. Por otro lado, tanto la mayor especulación moral (Kant) como el estudio más realista de la psique humana nos llevan a ampliar este modelo inscribiéndolo en el largo proceso de la transmisión.

Hay, sin embargo, una intuición inherente al modelo contractual que querríamos salvar: la exigencia de igualdad. El deseo de ser tratados de manera igual es posiblemente inherente (a excepción del heroísmo o la santidad, que desbordan el ámbito de la ética) a la idea de justicia en todas sus formas. Pero la cuestión es que esta igualdad no puede limitarse al equilibrio de prestaciones bilaterales suministradas por partes contratantes próximas y contemporáneas, sino que toma la forma de prestaciones diferenciadas en el tiempo, e intenta realizarse bajo figuras aparentemente tan desinteresadas como la de la donación y del auxilio, pudiendo afectar a terceros que, a primera vista, no tienen nada que ver con la obligación estipulada inicialmente. Aunque no podemos ofrecer aquí una completa descripción de las distintas formas que esta circulación de endeudamiento puede asumir en la red de la humanidad (entendida intergeneracionalmente), subrayaremos al menos la idea de que, en la mayoría de los casos, la transitividad de la obligación es en sí misma perfectamente capaz de satisfacer la exigencia de igualdad en situaciones caracterizadas por la asimetría, del mismo modo que la reciprocidad de las prestaciones lo hace en las situaciones simétricas.

${ }^{20}$ F. BLOCH, M. BUISSON, La circulation du don entre générations, ou comment reçoiton?, en Communications, nº 59, 1994 (Générations et filiation), pp. 55 y ss. 
¿Qué razón puede haber para limitar la esfera ética a las situaciones simétricas, si éstas constituyen, sin duda, sólo uno de los diferentes tipos de interacción humana? ¿Habrá marcado el modelo del mercado nuestra visión del mundo hasta tal extremo que tengamos serias dificultades para imaginar el intercambio humano en otros términos?

La idea de responsabilidad hacia las generaciones futuras nos parecerá menos incongruente si recordamos que, gracias a la transitividad inherente a la práctica de la transmisión, se restablece una forma de igualdad de las prestaciones - una igualdad ciertamente diferenciada en el tiempo y que se realiza entre personas diferentes, pero que parece acorde con las situaciones más corrientes caracterizadas por la diferencia de posición entre los protagonistas. En el modelo del contrato, las prestaciones se equilibran entre A y B; si tal equilibrio se logra, se hablará de justicia conmutativa. Se configurará un modelo en bucle para sellar el intercambio ente A y B: se habrá formado una «burbuja social» de la que se podrá admirar la puridad. Pero este modelo es en realidad excepcional, la mayor parte de interacciones humanas se producen sobre todo en una «cadena abierta», cuyo propósito no es tanto producir eslabones separados («burbujas» contractuales), como establecer las conexiones entre ellos. La lógica de la transitividad parte entonces de la lógica de la reciprocidad: un equivalente de lo que $\mathrm{B}$ ha recibido de A se transmite a $C$, quien a su vez lo transmite a $\mathrm{D}$. Bien se trate de la problemática de las transferencias justas entre clases de edad o de la justa herencia entre cohortes, es en estos términos en los que se configura la exigencia de justicia intergeneracional. Un autor como Ph. van Parijs considera, por ejemplo, que el criterio de herencia justa es que el «potencial productivo dejado por la generación presente sea al menos igual al que le había sido legado por la generación precedente» ${ }^{21}$; por lo que se refiere al criterio de transferencia justa, éste se basa más en la idea de solidaridad que en la de equilibrio conmutativo: el objetivo es dar a nuestros hijos el equivalente a lo que nosotros mismos recibimos de la generación adulta cuando éramos niños (y no tanto darles lo que recibiremos de ellos más tarde). Del mismo modo, lo que determina el monto de nuestra obligación respecto a las personas mayores es lo que, en su tiempo, hicieron ellos mismos por sus mayores (más que compensar lo que ellos hicieron por nosotros cuando éramos niños) ${ }^{22}$.

Desde luego esto no implica negar las numerosas dificultades que se crearán con la introducción de esos criterios. Lo que importa en este punto de nuestra discusión es adoptar un tipo de razonamiento que oriente el de-

\footnotetext{
${ }^{21}$ Ph. VAN PARIJS, op. cit., p. 9.

${ }^{22}$ Ibid., pp. 9-10.
} 
bate ético con miras a ofrecer un fundamento razonado para la responsabilidad hacia las generaciones futuras. Lo que queremos sostener es que la asunción de responsabilidad hacia los más débiles (niños, personas mayores, generaciones futuras) no implica inscribirse en el intercambio contractual, ni endosar una obligación absolutamente unilateral, y por tanto heroica, sino simplemente situarse en la red de la transitividad constitutiva de la condición humana. Al mismo tiempo se salvaguarda una exigencia esencial de la modernidad: la reivindicación de la autonomía y de la igualdad del sujeto moral. Se puede mostrar, en efecto, que la lógica de la transmisión que hemos evocado se inscribe, para un autor como Van Parijs, en una teoría moral que se dirige a asegurar que los recursos se repartan de modo que la libertad real de los que tienen menos sea la mayor posible ${ }^{23}$. Para un autor como B. Barry, el criterio de «igual acceso de todas las generaciones a los recursos naturales» es muy similar al que aquí hemos discutido y se apoya en su afirmación principialista de la igualdad entre todas las generaciones (justicia como «igual oportunidad») ${ }^{24}$. En línea con el concepto kantiano de humanidad, es la idea de igual dignidad de todo ser humano (en sus dos sentidos de libertad real y de igualdad), independientemente de cuál sea su posición en la cadena de las generaciones, la que subyace a la lógica de la transmisión. Es importante subrayar este punto -sobre el que volveremospara eliminar aquellas interpretaciones de la transmisión según las cuales ésta implica una reducción de la autonomía de los donantes, del mismo modo que ocurre en algunas situaciones familiares alienantes y virtualmente patógenas. Al rechazar hacer uso de algún tipo de «derecho a nacer» respecto a las generaciones futuras, lo que estamos intentando, más que imponer un futuro dado, es mantener el más amplio espectro de posibilidades.

En defensa de este intento de desplazar la lógica de la estricta equivalencia, se podría todavía evocar la famosa «regla de oro» de la ética, al menos como ha sido reinterpretada por P. Ricoeur sobre la base del mandamiento de amar al enemigo. A primera vista, la antinomia entre las dos normas es profunda: por un lado, la regla de oro («no hagas a los otros lo que no quieras que te hagan a ti», «haz a los otros lo que quieres que te hagan a ti»), que parece formar parte de la lógica de la reciprocidad; y por otro lado el mandamiento de amar al enemigo, que refleja una forma de predisposición hacia la donación y que apunta hacia una lógica (¿locura?) de amor metaético. ¿Pero se reduce realmente la regla de oro a la reciprocidad de las relaciones de igualdad? Se observará de entrada que ella conduce a una situación asimétrica: el agente al cual se dirige parece en una posición de

\footnotetext{
${ }^{23} \mathrm{Ph}$. VAN PARIJS, Real Freedom for All, Oxford, 1995.

${ }^{24}$ B. BARRY, Justice as Reciprocity, op. cit., pp. 76 y ss.
} 
fuerza, capaz de causar un perjuicio grave al paciente. El objetivo de la máxima es entonces detener la fuerza del agente en consideración de la situación del otro, en cuyo lugar se le invita a situarse. ¿Es esto sólo una llamada a la prudencia? Se trataría en ese caso de abstenerse de perjudicar porque, quizá mañana, podría él mismo ocupar el lugar del paciente. Se subraya así la reversibilidad de la condición humana. Se trata sin duda de la interpretación más restrictiva de la regla de oro, que induce ciertamente a un mínimo de responsabilidad, pero se trata de una responsabilidad que sólo concierne a los que podrían dañarme (estar mañana en mi lugar) y ello se justifica sólo por una motivación utilitarista. No se escapa entonces del «do ut des»: es con el objetivo de conseguir un eventual beneficio para el mañana por lo que hoy ayudo a otro. Al fin y al cabo según esta primera interpretación, no nos hemos liberado de la vieja ley del talión, que es la forma más rudimentaria de la justicia conmutativa ${ }^{25}$.

Pero no está prohibido dar a la regla de oro una interpretación más generosa, inspirada en el mandamiento de amar al enemigo. Esta vez no se trata de dar para recibir, o de complacer para ser complacido, sino de dar porque ya se ha recibido ${ }^{26}$. Así interpretada, la máxima se libera de sus connotaciones utilitaristas, o regresivas (la ley del talión), y resulta aplicable a toda persona participante, incluso virtualmente, en la condición humana común, aunque todavía no esté en condiciones de afectarme (o aunque nunca lo llegue a estar en el sentido empírico del término). En este caso, el desplazamiento exigido por la máxima (ponerse en el lugar del paciente) será completo y desinteresado. Ya no se limita a las estrictas condiciones de la reversibilidad empírica (todos los casos figurativos en que uno pudiera, realmente esta vez, aceptar el rol del débil), sino que invita a asumir la humanidad del otro en toda su diferencia. Sin duda tal desplazamiento sólo es humanamente practicable en un clima de confianza engendrado por la prioridad de un amor ya recibido, según la lógica de la transmisión que encontramos aquí. Esta prioridad de la donación sobre la obligación establece una forma de reciprocidad en un contexto marcado por la asimetría, que vuelve así más aceptable la responsabilidad. En otro texto, Ricoeur señala el parentesco entre la máxima así interpretada y la segunda formulación del imperativo categórico kantiano («tratar a la humanidad en tu persona como en la persona de cualquier otro siempre como un fin y no como un medio») ${ }^{27}$ :

\footnotetext{
${ }^{25}$ Es interesante notar que en Lucas VI, 32-34, Jesús que, en ese contexto, compara el mandamiento del amor (Lucas VI, 27) con la regla de oro (Lucas VI, 31), condena firmemente esta interpretación «utilitarista» de la regla de oro. «Si dais lo que esperais recibir, ¿qué gracias tenéis?»

${ }^{26}$ P. RICOEUR, Amour et justice, Tübingen, 1990, p. 58.

${ }^{27}$ P. RICOEUR, Soi-même comme un autre, París, 1990, p. 225.
} 
el respeto de mi propia humanidad pasa por el respeto de la de los otros (incluso los muertos, los que no han nacido y los totalmente dependientes). No se trata de una simple cuestión de interés, sino de respeto a la ley moral: actuar al margen de la cadena de la transmisión, como si fuera el primer o último hombre, es situarme al margen de la humanidad, es comprometer mi propia humanidad. La reciprocidad aquí evocada no es del tipo de donantedonante, ya que el contexto es asimétrico. Dicho más básicamente, recuerda que el hombre privado de humanidad no es nada. Generalizando este análisis, Ricoeur concluirá que la regla de justicia (entendida como formalización de la regla de oro) oscila permanentemente entre esas dos interpretaciones: de la competencia entre intereses rivales que intentan extraer el máximo beneficio en los límites del principio de equivalencia, al otro extremo de la búsqueda de una auténtica cooperación «que llega hasta admitir estar en deuda unos con otros» ${ }^{28}$.

Ahora queda mostrar cómo proponemos superar el obstáculo que hemos llamado «instantaneísta». Todo lo que precede debería facilitarnos el trabajo. Ya hemos insistido en el hecho de que cada generación no aparezca «como un solo hombre» en el escenario de la historia, ni tampoco que la deje «en bloque». En ningún momento nos asiste una definición, tabula rasa, de las condiciones de la vida en sociedad. Tres generaciones cohabitan, cuyos deseos, temores, ideas y valores están al menos parcialmente interconectados. Esta interacción es la contraparte visible y concebible del vínculo que existe a gran escala y de manera más difusa entre las generaciones alejadas.

Lo que ahora querríamos subrayar es que esta situación, en tanto que sea reconocida y asumida, implica un «desplazamiento» general del pasado y el futuro, involucrándose ambos, a través del crisol de nuestras elecciones en el presente, en una articulación viva cuyo sentido no cesa de reelaborarse. Desde este punto de vista, la historia ya no se comprende como la crónica, lineal y fija, de los eventos que se suceden empujándose unos a otros hacia las lagunas de la memoria. Aparece sobre todo como una reinterpretación permanente -a la vez actuada y pensada- del pasado en términos de una reapropiación que se dirige a forjar los núcleos de sentido necesarios para la construcción del presente. Si recordamos las categorías de «espacio de la experiencia» $\mathrm{y}$ «horizonte de expectativa», podríamos decir que los datos de la memoria y de la experiencia son continuamente movilizados y reinterpretados en función de las expectativas del mañana, lo que al mismo tiempo confiere un futuro para el pasado y raíces para el futuro. Todo sucede entonces como si el pasado fuera menos cerrado y definitivo que lo que tendemos a creer, y como si todavía hubiera recursos que explorar que arroja-

\footnotetext{
${ }^{28}$ P. RICOEUR, Amour et justice, op. cit., p. 60.
} 
ran, retrospectivamente, una nueva luz; mientras que a la inversa, el futuro aparece menos indeterminado que lo que podría creerse, trazándose caminos proyectados por la experiencia del pasado. En beneficio de esta dialéctica temporal, la memoria podrá liberarse de las estrictas tradiciones muertas y de la crispación de los fundamentalismos ideológicos, mientras que a la inversa y por lo que respecta al futuro, la idea de progreso podrá recuperar su connotación de esperanza, siendo reconectada con una historia viva que se distinguirá de las imprecisas utopías ${ }^{29}$.

Insistamos aún más sobre esto. Esta fecundación recíproca del futuro y del pasado es lo contrario a un modelo alienante. Su efecto más seguro es garantizar una producción continua de sentido; dicho de otro modo, una reserva de aperturas posibles para la acción y la reflexión. Lejos de encadenar a las generaciones futuras en no se sabe qué programa preestablecido, preserva una pluralidad de orientaciones que cada generación puede, a su vez, reorganizar y hacer más complejas. Se podría decir, según la bella expresión de F. Collin, que «la herencia es intestada» ${ }^{30}$, o que si hay testamento, éste está abierto a tantas interpretaciones que el juego, lejos de terminarse, empieza completamente de nuevo.

A primera vista, todo esto podría parecer algo alejado de la problemática estricta de la responsabilidad hacia las generaciones futuras. En la literatura especializada en esta materia, se discute extensamente, por ejemplo, sobre las cuestiones técnicas de planificación y de cálculo de riesgos en situaciones de incertidumbre (¿qué podemos saber del resultado futuro de las decisiones que tomamos hoy?) ${ }^{31}$. Tales cuestiones son importantes y nos ocuparemos brevemente de ellas. Pero creemos que es mucho más importante restaurar primero el sentido de una comunidad intergeneracional, preguntándonos en qué condiciones nuestros predecesores, nuestros sucesores y nosotros mismos compartimos un destino común. Mientras no entendamos que lo que les ha ocurrido a ellos y lo que les ocurrió puede afectarnos hoy, las especulaciones sobre los efectos futuros de nuestras decisiones difícilmente serán algo más que un mero ejercicio académico.

${ }^{29}$ Sobre todo esto, cf. P. RICOEUR, Temps et récit, t. III, op. cit. p. 313.

${ }^{30}$ F. COLLIN, Un héritage sans testament, en La société des femmes, Les Cahiers du GRIF, Bruselas, 1992, pp. 109 y ss. (la expresión parece ser de René Char). La historia es a la vez continuidad y apertura; hay por tanto dos maneras de pararla: privándola de apertura, o negándole toda continuidad.

${ }^{31}$ De hecho, tenemos que admitir que cualquier concepción presente de (opciones para) un futuro es, por definición, determinada por nuestro conocimiento y visión del mundo actual. No se excluye que, después de todo, una opción que hoy parece ser la peor, se mostrará mañana como la mejor. Sólo las generaciones futuras serán capaces de juzgar si realmente tomamos las decisiones «correctas» o no. 


\section{Problemas de puesta en práctica}

Supongamos que hemos superado los dos obstáculos, el «contractualista» y el «instantaneísta». La responsabilidad hacia las generaciones futuras es ahora concebible. Queda ponerla en práctica. En este punto surgen miles de cuestiones de las que sólo señalaremos algunas y sólo para sugerir modos de razonamientos susceptibles de ligar las cuestiones de ética fundamental y los problemas de ética aplicada.

La primera cuestión es relativa a la naturaleza precisa del patrimonio a transmitir a las generaciones futuras. J. Locke quien, como es sabido, justifica la apropiación privada de recursos públicos, establece sin embargo una condición a decir verdad extremadamente exigente: que queden recursos «suficientes e igualmente buenos» ${ }^{32}$. Estrictamente hablando, esta condición prohibiría consumir los recursos naturales no renovables. También Ph. Van Parijs prefiere razonar en términos de «potencial productivo», suponiendo que las compensaciones podrían llevarse a cabo entre recursos naturales y productos de sustitución generados por los progresos tecnológicos. Lo importante es que se transmita de una generación a otra un potencial productivo equivalente (el potencial productivo se define como la cantidad de riqueza producible con una determinada cantidad de trabajo). Pero el autor no esconde las numerosas dificultades de la aplicación de este criterio. En primer lugar, es posible que el progreso técnico y la apropiación de los recursos naturales implique un deterioro irreversible del medio ambiente, afectando seriamente a la calidad de vida (la «libertad real») de las generaciones futuras. La lógica de la compensación encuentra aquí su límite. Más aún, es posible que las decisiones tecnológicas adoptadas (la apuesta nuclear, por ejemplo) generen riesgos excesivos para nuestros sucesores, y si tales riesgos se convierten en reales ello supondría transferencias dispares seriamente negativas (también es posible que, siendo conscientes de tales riesgos, las generaciones futuras tuvieran que invertir considerables sumas en tal prevención). Finalmente, es posible que el confort que disfrutamos hoy sólo haya sido posible gracias a un uso constante de «préstamos», cuyo pago, una vez más, hemos diferido a nuestros sucesores. El criterio de transmisión de un «potencial productivo» equivalente, aunque correspondiente a una intuición ética válida, plantea gran cantidad de cuestiones ${ }^{33}$. Esto mismo es lo que pasa con la noción de «patrimonio», que es su equivalente jurídico ${ }^{34}$.

${ }^{32}$ J. LOCKE, Second Treatise on Civil Government (Deuxième traité du gouvernement civil, trad. por B. Gilson, París, 1977, p. 93).

${ }^{33}$ Sobre todo esto, véase Ph. VAN PARIJS, op. cit., pp. 9-11.

${ }^{34}$ Cf. F. OST, La nature hors la loi. L'écologie à l'épreuve du droit, París, 1995, pp. 306-337. 
Tratar estas cuestiones implica aparentemente un ejercicio de futurología. Pero en este punto aparece un nuevo interrogante: si es verdad que tenemos «tanta responsabilidad como poder», ¿cómo determinar la extensión de ese poder y, en consecuencia, cómo se puede medir la amplitud de nuestras responsabilidades? ¿Cuál es el horizonte temporal apropiado para evaluar nuestras acciones? Más allá de un cierto punto, las incertidumbres se acumulan hasta el extremo de que los pronósticos serios se vuelven imposibles. ¿Deberíamos entonces volver a la regla elemental de prudencia que dice que debemos abstenernos de asumir cualquier riesgo irreversible que pueda, en un momento u otro, causar serios daños a nuestros sucesores? El problema sería entonces trazar una línea nítida entre lo reversible y lo irreversible.

Para responder a estas delicadas cuestiones, relacionadas con la dialéctica histórica de la que ya hemos hablado, hay que ocuparse de «dos modos de percepción deformada de la realidad: el escéptico y el utópico» ${ }^{35}$. En el primero, nada puede decirse del futuro, que se abandona a sí mismo; en el segundo, se asume que el futuro puede ser subyugado a nuestros pronósticos y programado a voluntad. El escéptico está completamente implicado en el momento presente, abandonando cualquier pretensión de predecir el futuro, en una actitud en la que el quietismo (sometido a la Providencia o al destino) es indudablemente confundido con el cinismo («après nous le déluge»). Por otro lado, el utópico pretende ser capaz de percibir «mañanas que funcionan», en cuyo nombre se cree estar autorizado a exigir -a veces por la fuerza- considerables renuncias en el presente; sobrestimando la pervivencia de los valores en que creemos, se imagina a sí mismo capaz de someter a las generaciones futuras a sus propias decisiones. Por supuesto, el futuro no es tan dócil como piensa; pero tampoco es totalmente imprevisible como cree el escéptico. La historia, repetimos, es al mismo tiempo continuidad y apertura, fruto de la dialéctica entre el «espacio de la experiencia» y el «horizonte de expectativa».

Esta sabiduría de la moderación en la apreciación del futuro podría igualmente servir de guía para la evaluación de las responsabilidades. La cuestión que aquí se plantea es la de saber en qué medida tener en cuenta los resultados colaterales inintencionales, los «efectos perversos» (los opuestos a aquello que se buscaba). Nos encontramos aquí con la cuestión de las consecuencias «previsibles» de la norma adoptada, las únicas consecuencias que, de acuerdo con Habermas, intervienen en el test de validez realizado por la discusión racional (cf. antes, el principio «U»). El problema es que los riesgos generados por la sociedad industrial son de una gra-

\footnotetext{
${ }^{35}$ D. BIRNBACHER, op. cit., pp. 151 y ss.
} 
vedad potencial tal que ya no podemos limitarnos a las consecuencias «previsibles» de nuestras decisiones. Sin embargo, ¿es posible calibrar totalmente nuestra acción en todas sus posibles consecuencias? El dilema de la responsabilidad podría por tanto expresarse como sigue: o no prestamos atención a ningún efecto colateral de nuestra acción, con el riesgo de ser deshonestos; o asumimos todas las posibles consecuencias de nuestra acción, con el riesgo de no ser capaces de actuar en absoluto ${ }^{36}$. En el primer caso, que está ligado a la actitud escéptica antes descrita, la responsabilidad es evaluada exclusivamente en términos de buena voluntad: la intención es lo único que cuenta y todas las consecuencias se atribuyen al azar. Llevado al límite, se roza la mala fe. En el segundo caso, por el contrario, se imputan al sujeto todos los efectos de su acción, incluyendo los que son opuestos a lo que originalmente pretendía. Curiosamente, como observa Ricoeur, esta actitud lleva tanto a considerar al sujeto responsable de nada (todo lo que puede hacer es esperar lo mejor) como de todo (la actitud terrorista que atribuye al sujeto histórico una culpabilidad universal) ${ }^{37}$.

Entre la visión demasiado estricta de una responsabilidad limitada a los efectos previsibles de la acción y la visión demasiado amplia de una responsabilidad ilimitada, conviene adoptar una vía intermedia que reenvía, necesariamente, a las decisiones políticas y a los criterios jurídicos que la sociedad experimenta, con toda incertidumbre, en su práctica cotidiana. La técnica jurídica toma aquí el relevo a la intuición ética. Respecto al futuro, impone nuevas obligaciones, tales como la necesidad de fundar las decisiones en el conocimiento; éste sería el caso de los «estudios de impacto», cuyo propósito es evaluar los efectos a corto, medio y largo plazo de nuestros proyectos de aprovechamiento de medios naturales. Esta obligación estaría reforzada ahora por el nuevo principio de precaución que recomienda una actitud prudencial en los frecuentes casos en los que el experto científico es inconcluyente (la incertidumbre en cuanto al efecto de una determinada elección no puede servir como excusa para no proteger el medio ambiente). De un modo más general, el objetivo de todo el reciente Derecho medioambiental ha sido establecer una actitud preventiva basada en la prudencia: prevenir es mejor que curar, particularmente cuando el efecto de la enfermedad es potencialmente mortal. Es especialmente con este espíritu con el que se desarrolla una responsabilidad objetiva que pretende sobre todo indemnizar las consecuencias de los riesgos engendrados por una actividad peligrosa, y no tanto identificar a los culpables de un error previo. Ligado

\footnotetext{
${ }^{36}$ En este sentido, véase P. RICOEUR, Le concept de responsabilité, en P. Ricoeur, Le juste, París, 1995, p. 68.

${ }^{37}$ Ibid., p. 66.
} 
al establecimiento de fondos de garantía y/o de seguros obligatorios, estos sistemas de responsabilidad objetiva pretenden asegurar una mejor cobertura de los riesgos industriales con un espíritu de solidaridad tanto entre profesionales como entre grupos de víctimas potenciales.

La dialéctica temporal que antes hemos descrito debería, sin embargo, ponernos en guardia: la idea no es que la práctica jurídica deba desaparecer en el futuro, que la idea de culpa se disuelva en el concepto técnico de riesgo, o que la idea de retribución personal deba perderse en una solidaridad aseguradamente anónima. En otras palabras: la responsabilidad, en el sentido clásico de imputación de una culpa previa al sujeto responsable que le exige responder con sus propios medios, mantiene su importancia incluso aunque su aplicación práctica, por lo que se refiere al daño medioambiental, siempre sea difícil. Sean cuáles sean las dificultades, sigue siendo necesario que la culpa reconocida sea castigada y, en este sentido, la re-examinación judicial de los sucesos pasados será en alguna medida instructiva para el incierto futuro que intentamos esbozar. La función del juicio conserva aquí todo su valor, no limitándose a saldar las cuentas del pasado; al determinar hoy (a propósito de hechos que pasaron ayer) dónde se encuentra la línea entre lo permitido y lo prohibido, el juicio nos ayuda a determinar nuestros «horizontes de expectativa» ${ }^{38}$.

Por otra parte, la idea de responsabilidad incluye otro sentido (más allá de la responsabilidad retrospectiva de la culpa y de la responsabilidad prospectiva de la prevención), que está mucho más enraizada en el presente. Se trata de la responsabilidad como la asunción colectiva de los asuntos de la sociedad, particularmente en relación con el medio ambiente. Aquí el Derecho también interviene de diferentes modos para asegurar la participación en el proceso de toma de decisión de los ciudadanos individuales, las asociaciones, compañías y autoridades públicas. Es interesante observar a este respecto los importantes «derechos procedimentales» que los individuos y sus asociaciones han conseguido progresivamente, el derecho a la información, a la consulta y a las compensaciones jurídicas, y que permiten una mayor implicación en la toma de decisiones medioambientales.

Esto nos conduce a la práctica deliberativa de la negociación tal y como se desarrolla cotidianamente en el régimen democrático. Como conclusión, insistimos sobre esto: no hay, por supuesto, otra opción que la democracia para asumir las cuestiones antes descritas. En ninguna circunstancia, por ejemplo, puede el consejo de los expertos sustituir a la deliberación demo-

${ }^{38}$ Sobre esta dialéctica entre los diferentes aspectos de la responsabilidad, cf. F. OST, $L a$ responsabilité, fil d'Ariane du droit de l'environnement, en Droit et Société, 1995, n 30-31, pp. 281-322. 
crática, incluso aunque tal consejo sea obviamente indispensable para la discusión. Más aún, esperamos haber mostrado que este proceso de negociación, fatalmente ligado al presente, no debería ni limitarse únicamente al intercambio conmutativo, ni verse exclusivamente en el horizonte de la contemporaneidad. La lógica de la transmisión y de la dialéctica temporal debería ayudar a abrir perspectivas que incluyeran la idea de cuidado de las generaciones lejanas. A este respecto será instructivo volver sobre el modelo rawlsaniano de la «negociación bajo el velo de la ignorancia», y sobre los principios «U» $\mathrm{y}$ «D» de Habermas, considerando a las generaciones futuras completamente integrantes de la discusión ${ }^{39}$.

En este sentido D. Laws relata una experiencia interesante de consulta pública ocurrida en el Estado de Maine (EE.UU.) sobre una propuesta para implantar una planta de tratamiento de deshechos radioactivos, una consulta que implicaba, a pesar de la ausencia de cualquier representante de las generaciones futuras, experimentar con razonamientos entre generaciones. Conviene destacar dos aspectos de esta experiencia, muy próximos a las ideas aquí defendidas. Por un lado D. Laws cuenta que, respecto a la evaluación de los riesgos futuros, la intuición fue expresada como sigue: «cualquier razonamiento respecto al futuro debería tener sus raíces en el pasado. El pasado es a veces la mejor, si no la única, base donde apoyarse para predecir el futuro» ${ }^{40}$. Por otro lado, a lo largo de esta negociación se hizo necesario hacer un esfuerzo por minimizar cualquier forma de «preferencia temporal» que privilegiara o perjudicara a grupos de personas por su ubicación en el orden temporal. Hay que habituarse a «tratar a los ausentes como si estuvieran presentes». En este proceso, los participantes fueron obligados a «exponer la idea de una comunidad de personas que pueden encontrarse en cualquier lugar del tiempo y de la sociedad y que, sin embargo, se perciben a sí mismas como compartiendo una vida o un destino común» ${ }^{41}$.

Del mismo modo que son generalmente los adultos quienes deciden sobre las cuestiones de «transferencia justa» entre diferentes grupos de edad, afectando a los niños y a los ancianos, son los «contemporáneos» los que deciden sobre las cuestiones de «herencia justa» entre cohortes, afectando a sus sucesores. La situación es inevitable; lo que importa es que de este modo los adultos y los contemporáneos se inscriben en la perspectiva transgeneracional de un «destino común». A este respecto, el paralelismo entre la

${ }^{39}$ Éste es de hecho el trabajo que B. BARRY lleva a cabo a partir de Rawls. Cf. B. BARRY, Theories of Justice, op. cit., pp. 149 y ss.; Justice between Generations, op. cit., pp. 276 y ss.

40 D. LAWS, Responsabilité transgénérationnelle et décisions publiques, en Communications, 1994, n 59, p. 270.

${ }^{41}$ Ibid. pp. 274-275. 
cuestión de las clases de edad y de las cohortes no es meramente fortuito. Es posible asumir que el modo en el que los adultos tratan a los niños pequeños y a las personas mayores proporcionará un buen test para la credibilidad de las políticas adoptadas respecto a las generaciones futuras. Si en el nivel conceptual es útil trazar la distinción entre las dos áreas (así por ejemplo, dar un trato exageradamente preferente a nuestros niños y ancianos, tendría por efecto comprometer aún más el futuro de las generaciones posteriores), es sin embargo muy probable que la racionalidad y generosidad de una política lejana se compruebe en sus circunstancias cercanas. Sería suficiente a este respecto ver cómo tratamos, aquí y ahora, a nuestros contemporáneos del tercer y cuarto mundo.

\section{Conclusión}

Hemos argumentado que el pensamiento contractualista, incluyendo el principio de reciprocidad, está tan firmemente inmerso en nuestro modo de pensar que es un serio obstáculo para concebir las obligaciones hacia las generaciones futuras. Por ello, autores destacados, como Habermas y Rawls, tienen serias dificultades para hacer frente a los problemas de la ética medioambiental, ya que sus modelos están basados en concepciones de comunidades de personas que conviven en un mismo período de tiempo.

Otro rasgo típico de este pensamiento contractualista es, según hemos sostenido, su enfoque ahistórico e individualista. Los hombres se independizan de su historia y de su comunidad. Parecen tener la posibilidad de decidir libremente, no siendo influidos por ninguna posición histórica o societaria. En todas las teorías basadas en este modo de pensar, de Rousseau a Rawls, de Hobbes a Habermas, se hace tabula rasa del pasado y el futuro parece estar completamente abierto. Los seres humanos están aislados de su historia. No son vistos como parte de una cadena histórica continua, sino como entidades atómicas que, al menos en alguna posición ideal, no tienen que tomar en cuenta ni el pasado ni el futuro.

En contra de esta aproximación común, hemos argumentado que un ser humano no puede ser apartado de la cadena de generaciones sucesivas. $\mathrm{Pa}$ ra tomar esto en cuenta, tenemos que partir de conceptos como «responsabilidad» $\mathrm{y}$ «traspaso de una herencia» $\mathrm{y}$ de principios como la «igualdad entre generaciones», y no de conceptos como «contrato»y «reciprocidad». El hecho de que somos lo que somos gracias a las generaciones previas, crea el deber de transferir unas condiciones similares para una buena vida a las generaciones futuras. Desde este punto de vista, todas las generaciones son iguales, sin ninguna reciprocidad.

A todo esto podemos añadir ahora dos observaciones a modo de conclusiones. En primer lugar, es interesante señalar cómo el concepto de con- 
trato está actualmente experimentando cambios fundamentales en la práctica jurídica desde la perspectiva del tiempo. Un «contrato» ya no es visto exclusivamente como una fotografía en un momento determinado del tiempo que vincula al futuro, como un texto o la voluntad que subyace a ese texto, que no puede ser afectado por ningún cambio futuro en el mundo externo, hasta que se elabore un nuevo contrato. Cada vez se acepta con mayor fuerza que un contrato puede ser interpretado bajo el contexto de un cambio de circunstancias. El principio abstracto de igualdad formal y la creencia en la necesidad de aceptación de alguna fuerza vinculante absoluta de la (presunta) voluntad subyacente al contrato (original) han sido parcialmente reemplazados por el principio de protección de las partes que se considera que están, estructuralmente, en la posición más débil: los trabajadores respecto a sus empresarios, los agricultores respecto a los terratenientes y, hoy especialmente, los consumidores respecto a los proveedores de bienes y servicios. Tales contratos ya no son interpretados exclusivamente a la luz de lo que ocurrió antes de que el contrato fuera firmado para revelar así el significado exacto del contrato. Las concretas consecuencias del contrato probablemente desventajosas para la parte más débil, se han convertido en hechos relevantes para determinar el alcance del contrato ${ }^{42}$. Un cambio de circunstancias puede volver al contrato en no equitativo para una de las partes. Los jueces han encontrado diferentes maneras de tener esto en cuenta (p. ej. la théorie de l'imprévision), y los legisladores les han provisto de instrumentos que les permiten determinar el alcance de los contratos sobre la base de los sucesos posteriores, tales como un poder general para controlar los efectos de un contrato contrario a los principios de buena $\mathrm{fe}^{43}$, equidad y justi$\mathrm{cia}^{44}$. Del mismo modo que las leyes, los contratos ya no son concebidos como cosas del pasado que vinculan obligatoriamente al presente y al futuro. Las circunstancias actuales pueden determinar, en gran medida, el alcance de los contratos y las leyes, e incluso anular la voluntad original de sus creadores. El Derecho es algo que se hace día a día, en cooperación entre todos los actores de este ámbito. No es algo que está ahí y que se encuentra completa y exclusivamente determinado por la voluntad previa de algún legisla-

${ }^{42}$ Un ejemplo reciente es el artículo 2 de la Ley belga de 23 de diciembre de 1998, que modifica la Ley de 19 de julio de 1991 sobre prácticas comerciales, introduciendo una sección que establece que un contrato entre un consumidor y un proveedor de bienes y servicios deberá ser siempre interpretado a favor del consumidor (art. 34.4) (Belgisch Staatsblad - Moniteur belge, 23 diciembre, 1998, p. 40703).

43 Ya incluido en el artículo 1134 del Código de Napoleón de 1804.

${ }^{44}$ Un poder general de este tipo sería el que confiere el Código civil holandés al juez, o el poder conferido al juez por el legislador belga para disminuir los daños fijados en un contrato (art. 1231.1 del Código civil belga, aprobado por el art. 4 de la Ley de 23 de noviembre de 1998, Belgisch Staatsblad - Moniteur belge, 13 de enero, 1999, p. 902). 
dor o de las partes de un contrato. El pasado está todavía en gran medida determinando el presente y el futuro, pero el presente puede «reformar» el pasado. Los jueces de hoy pueden interpretar y adaptar un contrato a la luz de las circunstancias, la información y los principios y valores prevalecientes en la actualidad.

Desde esta perspectiva podemos concluir que la aproximación contractualista a la teoría y filosofía jurídica parte de un modelo de contrato desfasado: una ahistórica concepción individualista del «contrato» que no encaja con nuestro enfoque de hoy en día.

Finalmente, hay que señalar que no sólo hay razones éticas altruistas para aceptar algún tipo de responsabilidad hacia las generaciones futuras, sino también razones egoístas. Al menos alguna perspectiva positiva sobre el futuro es una condición necesaria para dar hoy sentido a nuestra vida. ¿Cuál podría ser el sentido de nuestras vidas si sabemos que, después de algún desastre a escala mundial, ningún ser humano sobreviviría después del año 2010? Implicaría un problema de sentido a corto plazo: ¿para qué vivimos? Pero también implicaría un problema de sentido de la vida a largo plazo: ¿cuál puede ser el sentido de nuestras vidas, si sabemos que somos los últimos seres humanos, de modo que no habrá más género humano después de nuestra muerte? El sentido de nuestra vida está parcialmente determinado por una perspectiva histórica: no nos sentimos únicamente miembros de las comunidades presentes, tenemos raíces en el pasado y deseos para el futuro. Somos parte de una comunidad histórica. Nos encontramos a medio camino entre, por un lado, nuestros padres, abuelos y otros ancestros; y, por otro lado, nuestros hijos, nietos y otros descendientes. Los deseos y perspectivas para nuestro propio futuro es lo que da sentido a la vida de los jóvenes. Pero al envejecer, esos deseos personales son reemplazados, por un lado, por (buenos) recuerdos del pasado, que se intentan atesorar y, por otro lado, por deseos para el futuro, pero no tanto para uno mismo, cómo para las generaciones más jóvenes. Todo el mundo desea lo mejor para sus hijos y nietos. ¿Podría alguien vivir sabiendo que, pocos años después de su propia muerte, el mundo entero sería destruido por algún desastre ecológico predicho por los científicos? Incluso si alguien estuviera completamente seguro de morir antes de este desastre, le daría mucho menos importancia a la vida. Uno se preocuparía por sus hijos quienes, normalmente, se convertirían en las víctimas del desastre. Si el mismo desastre fuera predicho para después de un siglo, la vida sería más fácil para la generación presente, ya que podrían estar seguros de que sus hijos y nietos (ya nacidos) morirían antes del desastre. Pero la vida también cambiaría dramáticamente. Probablemente, hubiera alguna esperanza de que los avances tecnológicos permitieran a las generaciones futuras, antes del fin del siglo, resolver los problemas 
y encontrar alternativas, trasladándose, por ejemplo, a otros planetas e intentando «reconstruir» un «medio ambiente» más o menos normal que les permitiera sobrevivir a largo plazo. Pero esto significaría que la vida entonces se habría vuelto posible desde un punto de vista psicológico, ya que habría una esperanza real de que todavía hay un futuro para el género humano, aunque fuera en otros planetas.

Esta perspectiva para el futuro no es sólo cuestión de perspectiva individual (para la propia vida o la de los propios descendientes). Es también, en gran medida, cuestión de perspectiva para la comunidad. Mucha gente se preocupa por las perspectivas de las generaciones futuras aunque no tenga hijos y sepa que nunca va a tenerlos. El interés por la supervivencia del grupo, si es necesario incluso a costa de la propia vida, parece por otra parte ser una conducta muy «natural» entre los seres humanos. Se ha mostrado cómo muchas conductas animales suicidas sólo tienen sentido porque ayudan a garantizar la supervivencia del grupo o de la especie ${ }^{45}$. Incluso para la gente sin hijos la vida tendría poco sentido si supieran por adelantado que el mundo se destruirá poco después de su muerte. Desde luego, parece más fácil vivir con esa información, cuando ese fin del mundo está predicho para el año 3000 que cuando lo está para el 2100. Y el 2100 a su vez crea menos problemas que el 2050. La convicción de que el mundo será completamente destruido creará también más problemas que el saber que el género humano sobrevivirá, pero en peores condiciones que las actuales.

Parece apropiado concluir que una certidumbre actual sobre cualquier pérdida sustancial de la calidad de vida en un futuro no muy lejano afectará, al menos en alguna medida, al sentido de la vida y por ello a la calidad de vida de las generaciones presentes. Esto nos brinda una importante razón egoísta para procurar una buena vida para las generaciones futuras, sin necesidad de la «reciprocidad contractual».

(Trad. de Isabel Lifante Vidal)

${ }^{45}$ CROMBAG, H., Een manier van overleven: psychologische grondslagen van moraal en recht, Zwolle, Tjeenk Willink, 1983.

\section{DOXA 22 (1999)}

